\title{
CDISC SDTM Treatment Setting Terminology
}

National Cancer Institute

\section{Source}

National Cancer Institute. CDISC SDTM Treatment Setting Terminology. NCI Thesaurus.

Code $C 124308$

Terminology associated with the treatment setting codelist of the Clinical Data

Interchange Standards Consortium (CDISC) Study Data T abulation Model (SDT M). 